\title{
Quantitative imaging by pixel-based contrast-enhanced ultrasound reveals a linear relationship between synovial vascular perfusion and the recruitment of pathogenic IL-17A- F+IL-23+CD161+CD4+ T helper cells in psoriatic arthritis joints
}

\begin{abstract}
To develop quantitative imaging biomarkers of synovial tissue perfusion by pixel-based contrastenhanced ultrasound (CEUS), we studied the relationship between CEUS synovial vascular perfusion and the frequencies of pathogenic T helper (Th)-17 cells in psoriatic arthritis (PsA) joints. Eight consecutive patients with PsA were enrolled in this study. Gray scale CEUS evaluation was performed on the same joint immediately after joint aspiration, by automatic assessment perfusion data, using a new quantification approach of pixelbased analysis and the gamma-variate model. The set of perfusional parameters considered by the time intensity curve includes the maximum value (peak) of the signal intensity curve, the blood volume index or area under the curve, (BVI, AUC) and the contrast mean transit time (MTT). The direct ex vivo analysis of the frequencies of SF IL17AF+CD161+IL23+ CD4+ T cells subsets were quantified by fluorescence-activated cell sorter (FACS). In crosssectional analyses, when tested for multiple comparison setting, a false discovery rate at $10 \%$, a common pattern of correlations between CEUS Peak, AUC (BVI) and MTT parameters with the IL17A-F+IL23+- IL17A-F+ CD161+- and IL17AF+CD161+IL23+CD4+T cells subsets, as well as lack of correlation between both peak and AUC values and both CD4+T and CD4+IL23+Tcells, was observed. The pixel-based CEUS assessment is a truly measure synovial inflammation, as a useful tool to develop quantitative imaging biomarker for monitoring target therapeutics in PsA.
\end{abstract}

\section{Introduction}

Psoriatic arthritis (PsA) is a systemic immune-mediated disease, characterized by enthesitis, synovitis, and osteitis, associated to skin psoriasis, with marked clinical heterogeneity $[1,2]$ linked to PsA-specific, immune-related susceptibility risk loci such as HLA-B, PTPN22, TNFAIP3, and IL23R [3, 4].

The activation of interleukin (IL)-23 pathway and induction of IL-17 cytokine axis (IL-17A; IL-17F; IL22) have been identified as important immunopathological mechanisms in PsA joint inflammation, involving both the innate and adoptive immune response [5-7].

The upregulation of the pro-inflammatory IL-17 axis is supported by both the upregulation of the pro-inflammatory cytokines, especially IL-1 3 , IL- 6 and IL-17, IL-21, IL-22 and IL-23 in synovial tissue (ST), and synovial fluid (SF) [8-12], and by the expansion either of CD4+ Thelper cells, which produce IL-17A and IL-17F (Th17) [12-18] or CD8+IL-17-producing T cells [19] in the PsA joints.

Th17 are memory cells which display functional properties distinct from other CD4+ Th cells and express distinctive Th17 molecules, such as the lineage-defining transcription factor retinoid acidrelated orphan receptor gamma T (RORyt), the c-type lectin CD161 [20], the IL-23Rp19, the chemokine receptor 6 CCR6), and CCR4 [21, 22]. Either the levels of IL-17, or the frequencies of CD4+ Th17+, or CD8+ IL-17+ T cells in the peripheral circulation, as in SF, showed a significant relation to the systemic disease activity, both at the onset and the progression of PsA and RA [10, 19].

New investigational anti-interleukin chimeric and monoclonal antibody biologic agents targeting the Th17- IL-23 pathway (ustekimumab, secukinumab, ixekizumab, tildrakizumab, and guselkumab) and the bispecific TNF/IL-17 (bimekyzumamb)monoclonal antibodies, are under development in PsA [23, 24].

The introduction of targeted PsA therapeutics makes urgent the validation and application of quantitative imaging biomarkers for the assessment of the response to treatment. SonoVue, a second-generation pulse-inversion harmonic imaging contrast-enhanced ultrasound (CEUS) medium consists of inert gas-filled microbubbles, embedded by a phospholipid membrane, the size $<10 \mu \mathrm{m}$, characteristics that prevent them from leaving the vascular system. So it is a long 
persistence, pure Bblood pool contrast agent^ ${ }^{\wedge}$, unlike standard computed tomography-and magnetic resonance imaging-contrast agents. The analysis of time-intensity curves of dye kinetics allows a dynamic real-time imaging [25], thus making it favorable clinic-based tool to assess functional vascular parameters, such as perfusion and relative blood volume [26]. However, the distinctive pathophysiology of PsA synovitis, characterized since the disease onset, by a rapid vascular growth and tortuous blood vessels at the synovio-entheseal complex [27, 28], with inhomogeneous distribution, throughout the relapsing course of the disease [29], makes difficult the quantitative imaging assessment of synovitis by video intensity data. Hence, to develop quantitative imaging biomarkers for the automatic assessment of synovial tissue perfusion, we adopted a novel quantification approach of pixel-based analysis, that derives kinetic parameters for each pixel within the synovial area. [30].

The main goal of the study was the assessment of the relationship of CEUS perfusion kineticswith the direct ex vivo SF analysis of pro-inflammatory Th17 cells subset in a cohort of PsA patients with active synovitis.

The pixel-based CEUS reveals a linear relationship between synovial vascular perfusion and the recruitment of pathogenic IL-17A-F+IL-23+ CD161+ CD4+ T helper cells in PsA joints.

\section{Material and methods}

\section{Patients}

Eight consecutive patients who fulfilled the Classification of Psoriatic ARthritis (CASPAR) criteria were enrolled in this study [31]. The clinical and demographic characteristics of PsA patients are reported in Table 1. SF samples were obtained from patients with active knee arthritis and SF effusion. In particular, the study of Tcell phenotypes was carried out in SF from eight PsA patients. The study was approved by the local Ethic Committee of the University Hospital of Padova (Italy) (number 52723; October 11, 2010), and written informed consent was obtained from each participant in accordance with the principles outlined in the Declaration of Helsinki, after being informed about the intent and the methodology of the study.

\section{PB and SF mononuclear cell preparation}

SF samples were collected from the swollen knees, centrifuged at $1000 \times \mathrm{g}$ to remove cells and debris; the SF samples were analyzed for total white blood cell (WBC) count (WBC/ $\mu \mathrm{l})$. PB mononuclear cells (PBMC) and synovial fluid mononuclear cells (SFMC) were isolated from the PB and SF by FicollPaque Plus (GE Healthcare) density gradient centrifugation. Isolated mononuclear cells were washed twice and adjusted to $0.5-1 \times 106$ cells/100 $\mu$ for immunostaining.

\section{Flow cytometry analysis}

Mononuclear cells were treated for $30 \mathrm{~min}$ at room temperature with commercially available FITC-, PE-, or PE-Cy5-conjugated monoclonal antibody (mAb): anti-CD4 (Becton-Dickinson Biosciences, Italy), anti-IL23R (R\&D Systems Inc., Minneapolis, MN, USA), and anti-IL-17 (R\&D Systems); antiCD161 (Becton-Dickinson Biosciences, Italy). FITC-, PE-, or PE-Cy5-conjugated isotype-matched mouse mAb was used to set the fluorescence background (IgG1 and IgG2a, BD Pharmigen).

Appropriate isotype controls and fluorescence minus one (FMO) controls were used to assign gates. Expression of the cytoplasmic cytokine was evaluated as previously described [15]. CD4+ T cells were gated with two different approaches: physical characteristic of cells and expression of CD4 in the area of lymphocytes to identify the T helper cells. Fluorescence-activated cell sorter (FACS) analysis was assessed as previously described, briefly, $5 \times 105$ cells were acquired on FACSCalibur 6 analyzer (Becton-Dickinson) and data processed by DIVA software program (Becton-Dickinson Biosciences, Italy). To evaluate whether differences between peaks were statistically significant with respect to controls, the Kolmogorov-Smirnov test was used. 


\section{Gray scale CEUS evaluation}

Gray scale CEUS evaluation was performed on the same joint immediately after joint aspiration. Before contrast-enhanced study, gray scale US examination was performed with a linear 7.5-13 MHz array transducer by experienced sonographers. Standardized anatomic guidelines of the scan in three recesses of the knee-superpatellar recess (SPR) and lateral and medial parapatellar recesses (LPPR and MPPR)-were used [32]. SPR was evaluated by scanning the zone between the prefemoral (posterior suprapatellar) fat pad and the upper margin of the femoral cartilage (supine position, knee joint extended, and bicipes femoris at rest). At the level of LPPR and MPPR, the vertical edge along the lateral and medial margins of the knee cap (bicipes femoris contracted) was identified by scanning.

Contrast-enhanced US examinations were performed by means of US apparatus (Hitachi HI Vision Ascendus; Hitachi Medical Systems Europe Sumpfstrasse 13, CH-6300 Zug), which was specifically designed for sonographic examinations with a contrast agent. A contrast agent composed of sulfur hexafluoride-filled microbubbles (SonoVue, Bracco International B.V., Amsterdam, Nederlands) was used.

Hitachi's wideband pulse inversion contrast harmonic imaging (dCHI-W) allows the modulation of the phase and transmitted frequency range between pulses. Advantages include significantly improved lateral and contrast resolution, without compromising axial resolution. Frequency modulation provides greater sensitivity at depth, compared with conventional harmonic imaging. All patients gave their informed consent for the use of contrast agent. A 4.8-mL bolus of contrast agent was injected into a peripheral vein and was followed by an injection of $10 \mathrm{~mL}$ of physiologic saline solution.

Immediately after the injections, the synovial tissue under examination was scanned with a frame rate of 15 frames per second. The transducer was kept in a fixed position to highlight all the phases of enhancement. The beam focus was placed at the level of the synovial proliferation or immediately below it, and beam gain was set at the minimum level. The apparatus in question affords the recording and filing of the images in digital format, and all the dynamic phases of the examination performed during $60 \mathrm{~s}$ were saved using this system.

\section{Pixel-wise quantitative analysis of CEUS data}

CEUS quantification at the pixel level has been shown to be more effective than region of interest (ROI)-based approaches in the characterization of different perfusion patterns in arthritis subtypes [30]. Moreover, the heterogeneity of CEUS kinetics makes the gamma-variate model insufficient to fully describe the behavior of the tracer, whose time appearance cannot be modeled as a flow any more, appearing as a trapping. Thus, we modeled the perfusion data derived by CEUS with the single recirculation component model (SCR) [33], by adding to the gamma-variate function an additional component of the integral of the gamma, that represents this apparent trapping of the microbubbles in the microvascular areas of significantly delayed synovial flow [34]:

$$
\begin{gathered}
c_{S C R}(\boldsymbol{p}, t)=c_{\text {gamma }}(\boldsymbol{p}, t)+c_{\text {slow }}(\boldsymbol{p}, t) \quad t \geq t_{0} \\
c_{\text {gamma }}(\boldsymbol{p}, t)=a_{0} \cdot\left(t-t_{0}\right)^{\alpha} \cdot e^{-\frac{t-t_{0}}{\beta}} t \geq t_{0} \\
c_{\text {slow }}(\boldsymbol{p}, t)=a_{1} \int_{t_{0}}^{t} c_{\text {gamma }}(\boldsymbol{p}, \tau) d \tau \quad t \geq t_{0}
\end{gathered}
$$

where $\boldsymbol{p}=\left[a_{0}, \alpha, t_{0}, \beta, a_{1}\right]$ is the vector of the model parameters

After linearizing the ultrasound log-compressed data as in [35], we solved the model for each element of the image (i.e., pixel-wise approach) with a Bayesian approach [36], deriving the complete distribution in the synovia of several perfusion parameters. These include the shape parameters of the perfusion model, the contrast mean transit time (MTT), and the blood volume index (BVI), as reported in Fig. 1. In order to describe the heterogeneity of distinct synovial flows as well as the presence of small areas of characteristic flow patterns of physiopathology significance, the 
distribution of each parameter over all pixels is summarized by four statistical descriptors: mean, standard deviation, 25th percentile, and 75th percentile. This allows us to explore the importance of both the global perfusion patterns in the synovia and their variability. In particular, the distribution percentiles return informationon the areas of the synovia characterized by the lowest or highest values of the parameters of interest, that can be important in case of localized foci of inflammation (Fig. 2).

\section{Statistical analysis}

To verify the relationship between the noninvasive imaging perfusion patterns and the local levels in the synovia of Th17 cells, we evaluated the Spearman's correlation coefficient between the parameters derived from the quantitative analysis of CEUS data and the frequencies of CD4+ T cell subsets. In order to accommodate for the scarcity of data, $p$ values of the correlations were computed using permutation test.

Given the high number of correlations to be tested and the small sample size, we also need to adjust the statistical significance considering multiple comparison. However, the Bonferroni [35] or the Holm-Bonferroni corrections have been shown to be too conservative in many settings (such as the one presented in this paper): we thus applied the false discovery rate (FDR) method [37] to control the amount of Type I error, setting the amount of FDR to $10 \%$. In any case, in order to account for possible Type II error, we also report the estimated $p$ values for single test.

\section{Results}

The dot plot mean and standard deviation of the frequencies of CD4+ T cell subsets are reported in Fig. 3, the upper and bottom panel, respectively. CEUS evaluation The significant values of CEUS correlations are reported in Table 2 and Supplementary Table. Single comparison test showed significant correlation between CD4+ IL17AF+IL23+ CD161+ T cell subset and heterogeneity of the time to peak in the synovium (rho $=0.74, p<0.05$ ), with the $25^{\text {th }}$ percentile of MTT (rho $=-0.85, p<$ 0.01 ) and with the $75^{\text {th }}$ percentile of $B V I$ ( $r h o=0.80, p<0.05$ ). When tested for multiple comparison setting a FDR at $10 \%$, only MTT resulted significant, with BVI being close to significant (alpha $=0.12$ ) (Table 2).

The correlations between CEUS parameters and the distinct T cell subtypes studied by FACS analysis are reported in Supplementary Table, showing the lack of correlation between both peak and AUC (BVI) values and both CD4+ and CD4 + IL23+ T cells subset, which show correlations with the heterogeneity of T peak and BVI. MTT shows a positive relation with CD4+ T cell frequency. On the contrary, there is a common pattern of correlations between CEUS Peak, AUC (BVI), and MTT parameters with the IL17A-F+IL23+ - IL17A-F+CD161+ - and IL17AF+CD161+IL23+ - CD4+ T cells subsets. Interestingly, all these CD4+ T cell subsets show negative correlations with MTT.

\section{Discussion}

The validation and application of quantitative imaging biomarkers is critical for the early assessment of the patient's response to treatment. Advanced tracer development, image acquisition, and image analysis have been used to produce quantitative biomarkers of pathophysiology [38]. Noninvasive and mini-invasive imaging measurement of angiogenesis plays an emerging role in both tumor and joint pathologies $[39,40]$. The real-time imaging, the high-spatial resolution, and the low costs represent the main advantages of CEUS, compared to other imaging modalities. However, a major drawback to develop quantitative imaging biomarkers for PSA by the conventional CEUS method is the heterogeneity of the distribution of the level of synovial enhancement that may affect the accurate quantification of synovial perfusion over the entire synovial area. In this study, we implemented the automatic assessment of the video intensity data with a new quantification approach of pixel-based analysis [30].

Unlike the conventional region of interest (ROI), pixel level analysis allows one to produce parametric maps of the same spatial resolution as the original CEUS image, as well as provides the localization of perfusion patterns and the evidence of kinetics differences [30]. The gamma-variate 
model of kinetic analysis was adopted, which is a more general, flexible, and physiological version of the traditional mono-exponential model, which already allowed to devise the relation between microvascular density and CEUS refilling time [32]. Nevertheless, the heterogeneity of CEUS kinetics as that observed in PsA synovitis [30] makes the gamma-variate model insufficient to fully describe the behavior of the tracer during the scan time length. In fact, by increasing the resistance to synovial vessel flow, the passage of the microbubbles through the highly irregular architecture of neoformed capillary network is slowed down, causing either the prolongation of the refilling time, or failure to identify the washout within the experimental time of the CEUS examination. So, it is not possible to model it as a flow any more, but it appears as a trapping. To obtain a comprehensive description of the synovial microbubble behavior in the pixel-based analysis, we modeled the perfusion data derived by CEUS, with the single recirculation component model, by adding to the gammavariate function an additional component of the integral of the gamma. This model represents the apparent trapping of the microbubbles in the microvascular areas of significantly delayed synovial flow [33, 34].

In the arthritis joints, the complex interplay between IL-1 $\beta$, IL-6, and IL-23 cytokines results in the specification of proinflammatory T helper cells [41-43]. Pathogenic CD4+Th17 cells were already characterized ex vivo and in vitro in PsA joints, by both the membrane expression of IL-17A, IL-6R $\alpha$, IL-22, IL-23p19R, INF- $\gamma$, CD161, CCR4, and CCR6, and the intracellular expression of IL17A, IL-22, RORC $\gamma$, JAK2, and STAT3 [10, 14, 15].

Since the presence in Th17 cells in either peripheral circulation, synovial fluid and synovial tissue, they can represent a credible immunopathological indicator of the PsA inflammatory process. In a translational approach to identify quantitative biomarkers of synovial angiogenesis, we compared the assessment of CEUS synovial perfusion with CD4+ T helper cell at the site of joint inflammation. To this end, a direct ex vivo FACS analysis of Th17 cell phenotypes was performed, by studying untouched freshly isolated SF-MNC of PsA patients, since the in vitro-cultured PMA and ionomycinstimulated CD4+ T cells do not necessarily reflect the natural levels of cytokine-secreting cells [15]. The key finding of the cross-sectional study is the linear relationship between CEUS perfusion kinetic and frequency of pathogenic Th17 cellular immigration in the joints of patients affected by PsA. The single and multiple comparison statistical analysis, using the permutation test and false discovery rate method $[35,37]$, suggests the reliability of the association between Th17 cells and Peak, MTT, or AUC, against the simply bystander effect of passive blood inflow of T cells in the joint cavity. The results of the study may improve the knowledge of the pathophysiology of PsA synovitis, since the pathogenic functional properties already shown by Th17 cells in arthritis joints [44, 45]. Indeed, Th17 cells exhibited the ability to activate synovial fibroblasts, to induce IL-6, IL-8, and tissue destructive enzyme matrix metalloproteinase- 1 and -3 , and to survive and persist in the inflamed and hypoxic joint $[10,16,46,47]$.

The CD161, a c-type lectin, also expressed by natural killer cells (NK) and NK- T cells, interacts with the acid sphingomyelinase (ASM, ceramide), a lipid hydrolase $[47,48]$ by inducing Th17 cells proliferation [48], and mediating chemotactic-independent trans-endothelial migration of human $\mathrm{T}$ cells [49].

The close relationship between Th17 frequencies in PsA joints and the accurate imaging quantification of synovial microvascular perfusion, both of which represent objective measures of joint inflammation, may reflect the link between the intensity synovitis and the dynamic process of endothelial interaction and transmigration of the helper memory T cells in PSA joints. PDUS examination was already shown to be an effective diagnostic tool in early PsA and psoriasis patients, also allowing the detection of subclinical synovitis $[50,51]$. In pioneer study in RA affected patients, synovial PDUS scores were found associated to the frequency of total IL-17 producing SF CD4+ T cells, after in vitro stimulation [52]. Recently, an elegant study in early RA demonstrated the relationship between quantitative assessment of power Doppler area and histologically determined synovial vascular area. Notably, large- and medium-sized vessels contributed for over $90 \%$ to the overall vascular area [53]. Instead, the limitations by the PDUS method at slow blood flow velocities 
and in small blood volumes vessels, Sonovue $\mathrm{C}$ agent, that follows the distribution kinetics of red blood cells can also refill the distal capillary network, allowing the accurate quantitative assessment of the whole synovial tissue microvascular flow. CEUS, compared with the unenhanced PDUS method, was indeed found to improve the detection of intra-articular vascularity either in RA [54], or PsA [55], or spondyloarthritis (SPA) sacroiliitis [56], and PsA enthesitis [57], as well as to be related to synovial vascular density in PsA [32]. Until now, the interrelationship between inflammation and angiogenesis in PsA synovitis, and the molecular mechanism of altered vascular morphology [54, 58], are not well understood. The proangiogenic activity of IL-17 has been well documented in arthritis and tumors [59,60], as IL-17 can up-regulate the constitutive release of angiogenesis factors by synovial fibroblasts $[12,61,62]$ and, in synergy with TNF- $\alpha$, can induce endothelial migration and invasion [63]. Notably, by studying the anti-angiogenic action of both systemic and local TNFblocking treatment in PsA [64], a selective depletion of the immature microvasculature was described during early RA disease [65]. That was also reflected by the distinct intrasynovial spatial configuration of the capillary network in response to TNF-blocking therapy in RA and PsA joints [55, 66]. These findings may indicate the potential advantage for a therapeutic targeting a selective microvascular district. The field of vascular-targeted therapeutics for the treatment of arthritis, by targeting the antigens specifically expressed in the micro-vasculature, is still in preclinical phase [40]. The ultrasound-based molecular imaging by the use of the Bnext generation^ ${ }^{\wedge}$ of microbubble-mediated ultrasound therapy, to bind and deliver drugs to target-specific sites [67-69], is rapidly expanding. In this view, the development of quantitative perfusion biomarkers of synovial angiogenesis is becoming of increasingly importance. In conclusion, the linear relationship between the PEAK, time of PEAK, and AUC of contrast-signal intensity values of synovial perfusion and the frequencies of CD161+IL-17+IL$23+$ CD4+ Th17 cells in the joints of patients affected by active PsA synovitis, indicating that pixelbased CEUS assessment truly measures synovial inflammation in the highly heterogenous microvascular environment of PsA joints, as a useful tool to develop quantitative imaging biomarker for monitoring target therapeutics in PsA.

\section{References}

1. Gladman DD, Antoni C, Mease P, Clegg DO, Nash P (2005) Psoriatic arthritis: epidemiology, clinical features, course, and outcome. Ann Rheum Dis 64(Suppl 2):ii14-ii17 2. Scarpa R,Ayala F, Caporaso N, Olivieri I (2006) Psoriasis, psoriatic arthritis, or psoriatic disease? J Rheumatol 33:210-212

3. Bowes J, Budu-Aggrey A, Huffmeier U, Uebe $\mathrm{S}$, Steel K, Hebert HL, Wallace C, Massey J, Bruce IN, Bluett J, Feletar M, Morgan AW, Marzo-Ortega H, Donohoe G, Morris DW, Helliwell P, Ryan AW, Kane D,Warren RB, Korendowych E, Alenius GM, Giardina E, Packham J,McManus R, FitzGerald O, McHugh $\mathrm{N}$, BrownMA, Ho P, Behrens F, Burkhardt $\mathrm{H}$, Reis A, Barton A (2015) Dense genotyping of immune-related susceptibility loci reveals new insights into the genetics of psoriatic arthritis. Nat Commun 6:6046

4. Budu-Aggrey A, Bowes J, Loehr S, Uebe S, Zervou MI, Helliwell P, Ryan AW, Kane D, Korendowych E, Giardina E, Packham J
McManus R, FitzGerald O, McHugh N, Behrens $F$, Burkhardt $H$, Huffmeier U, Ho P, Martin J, Castañeda S, Goulielmos G, Reis A, Barton A (2016) Replication of a distinct psoriatic arthritis risk variant at the IL23R locus. Ann Rheum Dis 75:1417-1418

5. Kirkham BW, Kavanaugh A, Reich K (2014) interleukin-17A: a unique pathway in immune-mediated diseases: psoriasis, psoriatic arthritis and rheumatoid arthritis. Immunology 141:133-142

6. Fitzgerald O, Winchester R (2009) Psoriatic arthritis: from pathogenesis to therapy.

Arthritis Res Ther 11:214

7. Tan WS, Kelly S, Pitzalis C (2016) Targeted therapies: what they teach us about the pathogenesis of psoriasis and psoriatic arthritis. Expert Rev Clin Immunol. doi:10.1080/1744666X.2017.1241710 8. van Kuijk AW, Reinders-Blankert P, Smeets TJ, Dijkmans BA, Tak PP (2006) Detailed analysis of the cell infiltrate and the 
expression of mediators of synovial

inflammation and joint destruction in the synovium of patients with psoriatic arthritis: implications for treatment. Ann Rheum Dis 15(65):1551-1557

9. Fiocco $U$, Sfriso $P$, Oliviero $F$, Roux-Lombard $P$, Scagliori E, Cozzi L, Lunardi F, Calabrese F, Vezzù $M$, Dainese $S$, Molena $B$, Scanu $A$, Nardacchione R, Rubaltelli L, Dayer JM, Punzi L (2010) Synovial effusion and synovial fluid biomarkers in psoriatic arthritis to assess intraarticular tumor necrosis factor$\alpha$ blockade in the knee joint. Arthritis Res Ther 12:R148

10. Leipe J, Grunke M, Dechant C, Reindl C, Kerzendorf U, Schulze- Koops H, Skapenko A (2010) Role of Th17 cells in human autoimmune arthritis. Arthritis Rheum 62:2876-2885

11. Celis R, Planell N, Fernández-Sueiro JL, Sanmartí R, Ramírez J, González-Álvaro I, Pablos JL, Cañete JD (2012) Synovial cytokine expression in psoriatic arthritis and associations with lymphoid neogenesis and clinical features. Arthritis Res Ther 14:R93 12. Raychaudhuri SP, Raychaudhuri SK, Genovese MC (2012) IL-17 receptor and its functional significance in psoriatic arthritis. Mol Cell Biochem 359:419-429

13. Jandus C, Bioley G, Rivals JP, Dudler J, Speiser D, Romero P (2008) Increased numbers of circulating polyfunctional Th17 memory cells in patients with seronegative spondylarthritides. Arthritis Rheum 58:23072317

14. Benham H, Norris P, Goodall J, Wechalekar MD, FitzGerald O, Szentpetery A, Smith M, Thomas R, Gaston H (2013) Th17 and Th22 cells in psoriatic arthritis and psoriasis.

Arthritis Res Ther 15:R136

15. Fiocco U, Accordi B, Martini V, Oliviero F, Facco M, Cabrelle A Piva L, Molena B, Caso F, Costa L, Scanu A, Pagnin E, Atteno M, Scarpa R, Basso G, Semenzato G, Punzi L, Doria A, Dayer JM (2014) JAK/STAT/PKC molecular pathways in synovial fluid T lymphocytes reflect the in vivo $T$ helper-17 expansion in psoriatic arthritis. Immunol Res 58:61-69 16. Moran EM, Heydrich R, Ng CT, Saber TP, McCormick J, Sieper J, Appel H, Fearon U, Veale DJ (2011) IL-17A expression is localized to both mononuclear and polymorphonuclear synovial cell infiltrates. PLoS One 6:e24048 17. van Baarsen LG, Lebre MC, van der Coelen $D$, Aarrass S, Tang MW, Ramwadhdoebe TH, Gerlag DM, Tak PP (2014) Heterogeneous expression pattern of interleukin 17A (IL-17A), IL-17F and their receptors in synovium of rheumatoid arthritis, psoriatic arthritis andosteoarthritis: possible explanation for nonresponse to anti-IL-17 therapy? Arthritis Res Ther 16:426

18. Dolcino M, Ottria A, Barbieri A, Patuzzo G, Tinazzi E, Argentino G, Beri R, Lunardi C, Puccetti A (2015) Gene expression profiling in peripheral blood cells and synovial membranes of patients with psoriatic arthritis. PLoS One 10:e0128262

19. Menon B, Gullick NJ,Walter GJ, Rajasekhar M, Garrood T, Evans HG, Taams LS, Kirkham BW (2014) Interleukin-17+CD8+ T cells are enriched in the joints of patients with psoriatic arthritis and correlate with disease activity and joint damage progression. Arthritis Rheumatol 66:1272-1281 20. Cosmi L, De Palma R, Santarlasci V, Maggi L, Capone M, Frosali F, Rodolico G, Querci V, Abbate $G$, Angeli R, Berrino L, Fambrini M, Caproni M, Tonelli F, Lazzeri E, Parronchi $\mathrm{P}$, Liotta F,Maggi E, Romagnani S, Annunziato F (2008) Human interleukin 17-producing cells originate from a CD161+CD4+ T cell precursor. J Exp Med 205:1903-1916

21. Korn T, Bettelli E, Oukka M, Kuchroo VK (2009) IL-17 and Th17cells. Annu Rev Immunol 27:485-517

22. Muranski P, Restifo NP (2013) Essentials of Th17 cell commitment and plasticity. Blood 121:2402-2414

23. Caso F, Del Puente A, Peluso R, Caso P, Girolimetto N, Del Puente A, Scarpa R, Costa L (2016) Emerging drugs for psoriatic arthritis. Expert Opin Emerg Drugs 21:69-79

24. Ritchlin CT, Krueger JG (2016) New therapies for psoriasis and psoriatic arthritis. Curr Opin Rheumatol 28:204-210 25. Morel DR, Schwieger I, Hohn L, Terrettaz J, Llull JB, Cornioley YA, SchneiderM(2000) Human pharmacokinetics and safety evaluation of SonoVue, a new contrast agent for ultrasound imaging. Investig Radiol 35:8085 
26. Rednic N, Tamas MM, Rednic S (2011) Contrast-enhanced ultrasonography in inflammatory arthritis. Med Ultrason 13:220227

27. Reece RJ, Canete JD, Parsons WJ, Emery P, Veale DJ (1999) Distinct vascular patterns of early synovitis in psoriatic, reactive, and rheumatoid arthritis. Arthritis Rheum 42:1481-1484

28. McGonagle D, Lories RJ, Tan AL, BenjaminM(2007) The concept of a Bsynovioentheseal complex ${ }^{\wedge}$ and its implications for understanding joint inflammation and damage in psoriatic arthritis and beyond. Arthritis Rheum 56:2482-2491

29. Fiocco U, Cozzi L, Chieco-Bianchi F, Rigon C, VezzùM, Favero E, Ferro $F$, Sfriso $P$, Rubaltelli L, Nardacchione R, Todesco S (2011) Vascular changes in psoriatic knee joint synovitis. J Rheumatol 28: 2480-2486 30. Rizzo G, Raffeiner B, Coran A, Ciprian L, Fiocco U,Botsios C, Stramare R, Grisan E (2015) Pixel-based approach to assess contrast-enhanced ultrasound kinetics parameters for differential diagnosis of rheumatoid arthritis. J Med Imaging (Bellingham) 2:034503

31. Taylor W, Gladman D, Helliwell $P$, Marchesoni A, Mease P, Mielants H, CASPAR Study Group (2006) Classification criteria for psoriatic arthritis: development of new criteria from a large international study. Arthritis Rheum 54:2665-2673

32. Fiocco U, Stramare R, Coran A, Grisan E, Scagliori E, Caso F, Costa L, Lunardi F, Oliviero F, Bianchi FC, Scanu A, Martini V, Boso D, Beltrame V, Vezzù M, Cozzi L, Scarpa R, Sacerdoti D, Punzi L, Doria A, Calabrese F, Rubaltelli L (2015) Vascular perfusion kinetics by contrast-enhanced ultrasound are related to synovial microvascularity in the joints of psoriatic arthritis. Clin Rheumatol 34:19031912

33. Patil V, Johnson G (2011) An improved model for describing the contrast bolus in perfusion MRI. Med Phys 38:6380-6383 34. G. Rizzo, M. Tonietto, M. Castellaro, A. Coran, B. Raffeiner, U. Fiocco, R. Stramare, E. Grisan (2017) Detection of a slow-flow component in contrast-enhanced ultrasound of the synovia for the differential diagnosis of arthritis', SPIE
Conference on Medical Imaging, Orlando (FL). Paper 10134-143

35. Dunn OJ (1961) Multiple comparisons among means. J Am Stat Assoc 56:52-64 36. Chappell MA, Groves AR, Whitcher B, Woolrich MW (2009) Variational Bayesian inference for a nonlinear forward model. IEEE Trans Signal Process 57:223-236

37. Benjamini Y, Hochberg Y (1995) J R Stat

Soc Ser B Methodol 57: 289-300

38. Prescott JW (2013) Quantitative imaging biomarkers: the application of advanced image processing and analysis to clinical and preclinical decision making. J Digit Imaging 26:97-108

39. Ehling J, Lammers T, Kiessling F (2013) Non-invasive imaging for studying antiangiogenic therapy effects. Thromb Haemost 109: 375-390

40. Ferrari M, Onuoha SC, Pitzalis C (2016) Going with the flow: harnessing the power of the vasculature for targeted therapy in rheumatoid arthritis. Drug Discov Today 21:172-179

41. Nistala K, Adams S, Cambrook H, Ursu S, Olivito B, de Jager W, Evans JG, Cimaz R, BajajElliott M,Wedderburn LR (2010) Th17plasticity in human autoimmune arthritis is driven by the inflammatory environment. Proc Natl Acad Sci U S A 107:14751-14756

42. Komatsu N, Okamoto K, Sawa S, Nakashima T, Oh-hora M, Kodama T, Tanaka S, Bluestone JA, Takayanagi H (2014) Pathogenic conversion of Foxp3+ T ce lls into TH17 cells in autoimmune arthritis. Nat Med 20:62-68

43. Fiocco U, Martini V, Accordi B, Caso F, Costa L, Oliviero F, Scanu A, FaccoM, BosoD, Gatto $M$, Felicetti $M$, Frallonardo $P$, Ramonda R, Piva L, Zambello R, Agostini C, Scarpa R, Basso G, Semenzato G, Dayer JM, Punzi L, Doria A (2015) Transcriptional network profile on synovial fluid T cells in psoriatic arthritis.

Clin Rheumatol 34:1571-1580

44. Miossec $P$ (2003) Interleukin-17 in rheumatoid arthritis: if $T$ cells were to contribute to inflammation and destruction through synergy. Arthritis Rheum 48:594-601 45. Paulissen SM, van Hamburg JP, DankersW, Lubberts $E$ (2015) The role andmodulation of 
CCR6+ Th17 cell populations in rheumatoid arthritis. Cytokine 74:43-53

46. van Hamburg JP, Asmawidjaja PS, Davelaar $\mathrm{N}$, Mus AM, Cornelissen F, van Leeuwen JP, Hazes JM, Dolhain RJ, Bakx PA, Colin EM, Lubberts E (2012) TNF blockade requires 1 , 25(OH)2D3 to control human Th17-mediated synovial inflammation. Ann Rheum Dis 71:606-612

47. Basdeo SA, Moran B, Cluxton D, Canavan M, McCormick J, Connolly M, Orr C, Mills KH, Veale DJ, Fearon U, Fletcher JM (2015) Polyfunctional, pathogenic CD161+ Th17 lineage cells are resistant to regulatory $\mathrm{T}$ cellmediated suppression in the context of autoimmunity. J Immunol 195:528-540 48. Bai A, Robson S (2015) Beyond ectonucleotidase: CD39 defines human Th17 cells with CD161. Purinergic Signal 11:317-319 49. Fergusson JR, Fleming VM, Klenerman $P$ (2011) CD161- expressing human T cells. Front Immunol 2:36

50. Naredo E, Möller I, de Miguel E, BatlleGualda E, AcebesC, Brito E, Mayordomo L, Moragues C, Uson J, de Agustín JJ, Martínez A, Rejón $E$, Rodriguez $A$, Daudén $E$, Ultrasound School of the Spanish Society of Rheumatology and Spanish ECO-Aps Group (2011) High prevalence of ultrasonographic synovitis and enthesopathy in patients with psoriasis without psoriatic arthritis: a prospective casecontrol study. Rheumatology (Oxford) 50:1838-1848

51. Freeston JE, Coates LC, Nam JL, Moverley AR, Hensor EM, Wakefield RJ, Emery P, Helliwell PS, Conaghan PG (2014) Is there subclinical synovitis in early psoriatic arthritis? A clinical comparison with gray-scale and power Doppler ultrasound. Arthritis Care Res (Hoboken) 66:432-439

52. Gullick NJ, Evans HG, Church LD, Jayaraj DM, Filer A, Kirkham BW, Taams LS (2010) Linking power Doppler ultrasound to the presence of th17 cells in the rheumatoid arthritis joint. PLoS One 5(9)

53. Kelly S, Bombardieri M, Humby F, Ng N, Marrelli A, Riahi S, DiCicco M, Mahto A, Zou L, Pyne D, Hands RE, Pitzalis C (2015) Angiogenic gene expression and vascular density are reflected in ultrasonographic features of synovitis in early rheumatoid arthritis: an observational study. Arthritis Res Ther 17:58 54. Fearon U, Griosios K, Fraser A, Reece R, Emery P, Jones PF, Veale DJ (2003)

Angiopoietins, growth factors, and vascular morphology in early arthritis. J Rheumatol 30:260-268

55. Fiocco U, Ferro F, Cozzi L, Vezzù $M$, Sfriso $P$, Checchetto $C$, Bianchi FC, Nardacchione R, Piccoli A, Todesco S, Rubaltelli L (2003) Contrast medium in power Doppler ultrasound for assessment of synovial vascularity: comparison with arthroscopy. J Rheumatol 30:2170-2176

56. Klauser AS, De Zordo T, Bellmann-Weiler $R$, Feuchtner GM, Sailer-Höck M, Sögner P, Gruber J (2009) Feasibility of second generation ultrasound contrast media in the detection of active sacroiliitis. Arthritis Rheum 61:909-916

57. Mouterde G, Aegerter P, Correas JM, Breban M, D'Agostino MA (2014) Value of contrast-enhanced ultrasonography for the detection and quantification of enthesitis vascularization in patients with spondyloarthritis. Arthritis Care Res (Hoboken) 66:131-138

58. Espinoza LR, Vasey FB, Espinoza CG, Bocanegra TS, Germain BF (1982) Vascular changes in psoriatic synovium.A light and electron microscopic study. Arthritis Rheum 25:677-684

59. Pickens SR, Volin MV, Mandelin AM II, Kolls JK, Pope RM, Shahrara S (2010) IL-17 contributes to angiogenesis in rheumatoid arthritis. J Immunol 184:3233-3241 60. Numasaki $M$, Watanabe $M$, Suzuki T, Takahashi H, Nakamura A, McAllister F, Hishinuma T, Goto J, Lotze

MT, Kolls JK, Sasaki H (2005) IL-17 enhances the net angiogenic activity and in vivo growth of human nonsmall cell lung cancer in SCID mice through promoting CXCR-2-dependent angiogenesis. J Immunol 175:6177-6189 61. Honorati MC, Meliconi R, Pulsatelli L, Canè S, Frizziero L, Facchini A (2001) High in vivo expression of interleukin-17 receptor in synovial endothelial cells and chondrocytes from arthritis patients. Rheumatology (Oxford) 40:522-527 
62. Moran EM, Connolly M, Gao W, McCormick J, Fearon U, Veale DJ (2011) Interleukin-17A induction of angiogenesis, cell migration, and cytoskeletal rearrangement. Arthritis Rheum 63:3263-3273

63. Hot A, Lenief V, Miossec $P$ (2012) Combination of IL-17 and TNF $\alpha$ induces a proinflammatory, pro-coagulant and prothrombotic phenotype in human endothelial cells. Ann Rheum Dis 71:768-776 64. Cañete JD, Pablos JL, Sanmartí R, Mallofré C, Marsal S, Maymó J, Gratacós J, Mezquita J, Mezquita C, Cid MC (2004) Antiangiogenic effects of anti-tumor necrosis factor alpha therapy with infliximab in psoriatic arthritis. Arthritis Rheum 50:1636-1641

65. Izquierdo E, Cañete JD, Celis R, Santiago B, Usategui A, Sanmartí R, Del Rey MJ, Pablos JL (2009) Immature blood vessels in rheumatoid synovium are selectively depleted in response to anti-TNF therapy. PLoS One 4:e8131 66. Fiocco U, Ferro F, Vezzù $M$, Cozzi L, Checchetto C, Sfriso P, Botsios C, Ciprian L, Armellin G, Nardacchione R, Piccoli A, Todesco
S, Rubaltelli L (2005) Rheumatoid and psoriatic knee synovitis: clinical, grey scale, and power Doppler ultrasound assessment of the response to etanercept. Ann Rheum Dis 64:899-905

67. Abou-Elkacem L, Bachawal SV, Willmann JK (2015) Ultrasound molecular imaging: moving toward clinical translation. Eur J Radiol 84:1685-1693

68. Put $S$, Westhovens R, Lahoutte T, Matthys $P$ (2014) Molecular imaging of rheumatoid arthritis: emerging markers, tools, and techniques. Arthritis Res Ther 16:208 69. Klauser A, Frauscher F, Schirmer M, Halpern E, Pallwein L, Herold M, Helweg G, ZurNedden D (2002) The value of contrastenhanced color Doppler ultrasound in the detection of vascularization of finger joints in patients with rheumatoid arthritis. Arthritis Rheum 46:647-653 
Tab. 1

Clinical and demographic characteristics of psoriatic arthritis patients included in the study. PsA psoriatic arthritis, $\mathrm{n}$ number, SD standard deviation, DMARDs disease-modifying antirheumatic drugs, ETN etanercept, PDN prednisolone, aDaily prednisolone dose $\leq 10 \mathrm{mg}$

Clinical and demographic characteristics of psoriatic PsA patients

Clinical and demographic characteristics

Patient numbers

Female, $\mathrm{n}(\%)$

Patient age, years, mean \pm SD

Disease duration, years, mean \pm SD

Gonarthritis duration, years, mean \pm SD

VES $\mathrm{mm} / \mathrm{h}(\mathrm{m} \pm \mathrm{DS})$

PCR $\mathrm{mg} / \mathrm{L}(\mathrm{m} \pm \mathrm{DS}$

$\mathrm{N}^{\circ}$ Tender jonts $28(\mathrm{~m} \pm \mathrm{DS})$

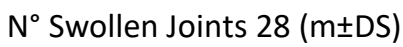

GH status 0-100 (mะDS)

DAS28-PCR $(m \pm D S)$

PASI (m $\pm D S)$

Systemic treatment at study entry

DMARDs, n (\%)

ETN, n (\%)

PDN, n (\%)
Values

8

$52.75 \pm 15.97$

$7.54 \pm 7.73$

$7.54 \pm 7.37$

$19.37 \pm 12.27$

$3.76 \pm 2.67$

$1.87 \pm 0.99$

$1.87 \pm 0.99$

$76.25 \pm 13.02$

$3.59 \pm 0.56$

$1.75 \pm 1.97$ 
Tab. 2

Correlations between the distinct contrast-enhanced ultrasound parameters (CEUS) (Spearman's correlation) and the frequencies of CD4+ IL17A IL17F+ CD161+ IL23+ T cells subset in synovial fluid of PsA patients, as detected by FACS analysis. Only significant values are reported, with their single comparison $p$-value and their multiple comparison alpha-value.

\begin{tabular}{|c|c|c|c|}
\hline \multicolumn{4}{|c|}{$\begin{array}{l}\text { Correlation between CEUS perfusion parameters and frequencies of } \\
\text { CD4+ IL17A-IL17F+ CD161+ IL23+ T cells synovial fluid of PsA }\end{array}$} \\
\hline \multicolumn{2}{|c|}{$\begin{array}{l}\text { Statistical descriptors of CEUS } \\
\text { perfusion parameters }\end{array}$} & $\begin{array}{l}\text { Single comparison } \\
\text { test }(p<0.05)\end{array}$ & $\begin{array}{l}\text { Multiple } \\
\text { comparison FDR }\end{array}$ \\
\hline \multirow{4}{*}{ 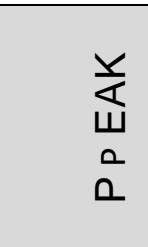 } & Mean & n.s. & n.s. \\
\hline & $\begin{array}{l}\text { Heterogeneity } \\
\text { (St. Dev.) }\end{array}$ & n.s. & n.s. \\
\hline & 25 perct & n.s. & n.s. \\
\hline & 75 perct & $0.74(0.02)$ & n.s. \\
\hline \multirow{4}{*}{$\stackrel{E}{\Sigma}$} & Mean & n.s. & n.s. \\
\hline & $\begin{array}{l}\text { Heterogeneity } \\
\text { (St. Dev.) }\end{array}$ & n.s. & n.s. \\
\hline & 25 perct & $-0.85(0.005)$ & $-0.85(0.065)$ \\
\hline & 75 perct & n.s. & n.s. \\
\hline \multirow{4}{*}{ 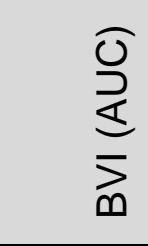 } & Mean & n.s. & n.s. \\
\hline & $\begin{array}{l}\text { Heterogeneity } \\
\text { (St. Dev.) }\end{array}$ & n.s. & n.s. \\
\hline & 25 perct & n.s. & n.s. \\
\hline & 75 perct & $0.80(0.02)$ & $0.80(0.12)$ \\
\hline
\end{tabular}


Tab. Suppl

Correlations between the different contrast-enhanced ultrasound parameters (CEUS) (Spearman's correlation) and the frequencies of different CD4+ T cells subsets in synovial fluid of psoriatic arthritis patients, as detected by FACS analysis. Only significant values are reported, with their single comparison pvalue and their multiple comparison alpha-value. 


\begin{tabular}{|c|c|c|c|c|c|c|c|c|c|c|c|c|c|}
\hline \multirow{2}{*}{\multicolumn{2}{|c|}{$\begin{array}{l}\text { Statistical descriptors } \\
\text { of CEUS perfusion } \\
\text { parameters }\end{array}$}} & \multicolumn{2}{|c|}{ CD4+ } & \multicolumn{2}{|c|}{ CD4+ IL17A-IL17F+ } & \multicolumn{2}{|c|}{ CD4+ IL23+ } & \multicolumn{2}{|c|}{$\begin{array}{c}\text { CD4+ IL17A-IL17F+ } \\
\text { IL23R+ }\end{array}$} & \multicolumn{2}{|c|}{$\begin{array}{c}\text { CD4+ IL17A-IL17F+ } \\
\text { CD161+ }\end{array}$} & \multicolumn{2}{|c|}{$\begin{array}{c}\text { CD4+ IL17A-IL17F+ } \\
\text { CD161+ IL23R+ }\end{array}$} \\
\hline & & $\begin{array}{c}\text { Single } \\
\text { comparison } \\
\text { Permutation } \\
\text { test }(\mathrm{p}<0.05) \\
\rho(\mathrm{p}-\mathrm{value})\end{array}$ & $\begin{array}{c}\text { Multiple } \\
\text { comparison } \\
\text { FDR test } \\
(\alpha<0.1) \\
\rho(\alpha)\end{array}$ & $\begin{array}{c}\text { Single } \\
\text { comparison } \\
\text { Permutation } \\
\text { test }(\mathrm{p}<0.05) \\
\rho(\mathrm{p} \text {-value })\end{array}$ & $\begin{array}{c}\text { Multiple } \\
\text { comparison } \\
\text { FDR test } \\
(\alpha<0.1) \\
\rho(\alpha)\end{array}$ & $\begin{array}{c}\text { Single } \\
\text { comparison } \\
\text { Permutation } \\
\text { test }(\mathrm{p}<0.05) \\
\rho(\mathrm{p}-\mathrm{value})\end{array}$ & $\begin{array}{c}\text { Multiple } \\
\text { comparison } \\
\text { FDR test } \\
(\alpha<0.1) \\
\rho(\alpha)\end{array}$ & $\begin{array}{c}\text { Single } \\
\text { comparison } \\
\text { Permutation } \\
\text { test }(\mathrm{p}<0.05) \\
\rho(\mathrm{p} \text {-value })\end{array}$ & $\begin{array}{c}\text { Multiple } \\
\text { comparison } \\
\text { FDR test } \\
(\alpha<0.1) \\
\rho(\alpha)\end{array}$ & $\begin{array}{c}\text { Single } \\
\text { comparison } \\
\text { Permutation } \\
\text { test }(\mathrm{p}<0.05) \\
\rho(\mathrm{p} \text {-value })\end{array}$ & $\begin{array}{c}\text { Multiple } \\
\text { comparison } \\
\text { FDR test } \\
(\alpha<0.1) \\
\rho(\alpha)\end{array}$ & $\begin{array}{c}\text { Single } \\
\text { comparison } \\
\text { Permutation } \\
\text { test }(\mathrm{p}<0.05) \\
\rho \text { ( } \mathrm{p} \text {-value })\end{array}$ & $\begin{array}{c}\text { Multiple } \\
\text { comparison } \\
\text { FDR test } \\
(\alpha<0.1) \\
\rho(\alpha)\end{array}$ \\
\hline \multirow{4}{*}{ 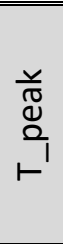 } & Mean & n.s. & n.s. & n.s. & n.s. & n.s. & n.s. & n.s. & n.s. & n.s. & n.s. & n.s. & n.s. \\
\hline & $\begin{array}{l}\text { Heterogeneity } \\
\text { (Std Dev) }\end{array}$ & $\begin{array}{c}-0.90 \\
(0.002)\end{array}$ & $\begin{array}{c}-0.90 \\
(0.022)\end{array}$ & n.s. & n.s. & n.s. & n.s. & n.s. & n.s. & n.s. & n.s. & n.s. & n.s. \\
\hline & 25 prct & n.s. & n.s. & n.s. & n.s. & n.s. & n.s. & n.s. & n.s. & n.s. & n.s. & n.s. & n.s. \\
\hline & $75 \mathrm{prct}$ & n.s. & n.s. & n.s. & n.s. & n.s. & n.s. & n.s. & n.s. & n.s. & n.s. & n.s. & n.s. \\
\hline \multirow{4}{*}{ 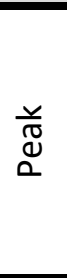 } & Mean & $\overline{\text { n.s. }}$ & $\overline{\text { n.s. }}$ & n.s. & n.s. & $\overline{\text { n.s. }}$ & n.s. & n.s. & n.s. & n.s. & n.s. & n.s. & n.s. \\
\hline & $\begin{array}{l}\text { Heterogeneity } \\
\text { (Std Dev) }\end{array}$ & n.s. & n.s. & n.s. & n.s. & n.s. & n.s. & n.s. & n.s. & n.s. & n.s. & n.s. & n.s. \\
\hline & $25 \mathrm{prct}$ & n.s. & n.s. & n.s. & n.s. & n.s. & n.s. & n.s. & n.s. & n.s. & n.s. & n.s. & n.s. \\
\hline & 75 prct & n.s. & n.s. & n.s. & n.s. & n.s & n.s. & $\begin{array}{c}0.74 \\
(0.021) \\
\end{array}$ & n.s. & $\begin{array}{c}0.64 \\
(0.047) \\
\end{array}$ & n.s. & $\begin{array}{c}0.74 \\
(0.021) \\
\end{array}$ & n.s. \\
\hline \multirow{4}{*}{$\begin{array}{l}\frac{0}{\frac{n}{2}} \\
\qquad\end{array}$} & Mean & n.s. & n.s. & n.s. & n.s. & n.s. & n.s. & n.s. & n.s. & n.s. & n.s. & n.s. & n.s. \\
\hline & $\begin{array}{l}\text { Heterogeneity } \\
\text { (Std Dev) }\end{array}$ & $\begin{array}{c}-0.86 \\
(0.006) \\
\end{array}$ & $\begin{array}{c}-0.86 \\
(0.066) \\
\end{array}$ & n.s. & n.s. & n.s. & n.s. & n.s. & n.s. & n.s. & n.s. & n.s. & n.s. \\
\hline & 25 prct & n.s. & n.s. & n.s. & n.s. & n.s. & n.s. & n.s. & n.s. & n.s. & n.s. & n.s. & n.s. \\
\hline & 75 prct & $\begin{array}{c}-0.75 \\
(0.019) \\
\end{array}$ & n.s. & n.s. & n.s. & n.s. & n.s. & n.s. & n.s. & n.s. & n.s. & n.s. & n.s. \\
\hline \multirow{4}{*}{$\begin{array}{l}\frac{r}{\tilde{n}} \\
\stackrel{m}{3}_{1} \\
⺊\end{array}$} & Mean & n.s. & n.s. & n.s. & n.s. & n.s. & n.s. & n.s. & n.s. & n.s. & n.s. & n.s. & n.s. \\
\hline & $\begin{array}{l}\text { Heterogeneity } \\
\text { (Std Dev) }\end{array}$ & n.s. & n.s. & n.s. & n.s. & n.s. & n.s. & n.s. & n.s. & n.s. & n.s. & n.s. & n.s. \\
\hline & 25 prct & n.s. & n.s. & n.s. & n.s. & n.s. & n.s. & n.s. & n.s. & n.s. & n.s. & n.s. & n.s. \\
\hline & $75 \mathrm{prct}$ & n.s. & n.s. & n.s. & n.s. & n.s. & n.s. & n.s. & n.s. & n.s. & n.s. & n.s. & n.s. \\
\hline \multirow{4}{*}{ E } & Mean & $\begin{array}{c}0.81 \\
(0.011)\end{array}$ & n.s. & n.s. & n.s. & n.s. & n.s. & n.s. & n.s. & n.s. & n.s. & n.s. & n.s. \\
\hline & $\begin{array}{l}\text { Heterogeneity } \\
\text { (Std Dev) }\end{array}$ & n.s. & n.s. & n.s. & n.s. & n.s. & n.s. & n.s. & n.s. & n.s. & n.s. & n.s. & n.s. \\
\hline & 25 prct & n.s. & n.s. & n.s. & n.s. & n.s. & n.s. & $\begin{array}{c}-0.85 \\
(0.006) \\
\end{array}$ & $\begin{array}{c}-0.85 \\
(0.077) \\
\end{array}$ & $\begin{array}{c}-0.71 \\
(0.028) \\
\end{array}$ & n.s. & $\begin{array}{c}-0.85 \\
(0.006) \\
\end{array}$ & $\begin{array}{c}-0.85 \\
(0.077) \\
\end{array}$ \\
\hline & 75 prct & n.s. & n.s. & n.s. & n.s. & n.s. & n.s. & n.s. & n.s. & n.s. & n.s. & n.s. & n.s. \\
\hline \multirow{4}{*}{ 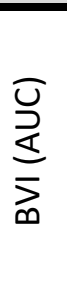 } & Mean & n.s. & n.s. & $\begin{array}{c}0.71 \\
(0.029) \\
\end{array}$ & n.s. & n.s. & n.s. & n.s. & n.s. & n.s. & n.s. & n.s. & n.s. \\
\hline & $\begin{array}{l}\text { Heterogeneity } \\
\text { (Std Dev) }\end{array}$ & $\begin{array}{l}-0.83 \\
(0.008)\end{array}$ & $\begin{array}{c}-0.83 \\
(0.091)\end{array}$ & n.s. & n.s. & n.s. & n.s. & n.s. & n.s. & n.s. & n.s. & n.s. & n.s. \\
\hline & $25 \mathrm{prct}$ & n.s. & n.s. & n.s. & n.s. & n.s. & n.s. & n.s. & n.s. & n.s. & n.s. & n.s. & n.s. \\
\hline & $75 \mathrm{prct}$ & n.s. & n.s. & $\begin{array}{c}0.76 \\
(0.019)\end{array}$ & $0.71(0.029)$ & n.s. & n.s. & $\begin{array}{c}0.80 \\
(0.011)\end{array}$ & n.s. & n.s. & $\begin{array}{c}0.80 \\
(0.011)\end{array}$ & n.s. & n.s. \\
\hline
\end{tabular}


Fig. 1

Analysis of IL-17A-F+ IL-23R+ CD161+ CD4+ T cells phenotypes in SF of PsA patients. Representative dot plots showing the CD161+ T cells gated on T CD4+ cells, and the CD4+IL-17A-F+ and CD4+IL$23 \mathrm{R}+$ cells, gated on the CD161+CD4+ T cells in the synovial fluid (SF) of psoriatic arthritis patients (PsA). (upper panel) and the frequencies of the distinct CD4+ Thelper cells subsets in the SF of PSA patients (bottom panel). Data represented as mean \pm SEM. Significance calculated by Student's $t$ test

upper
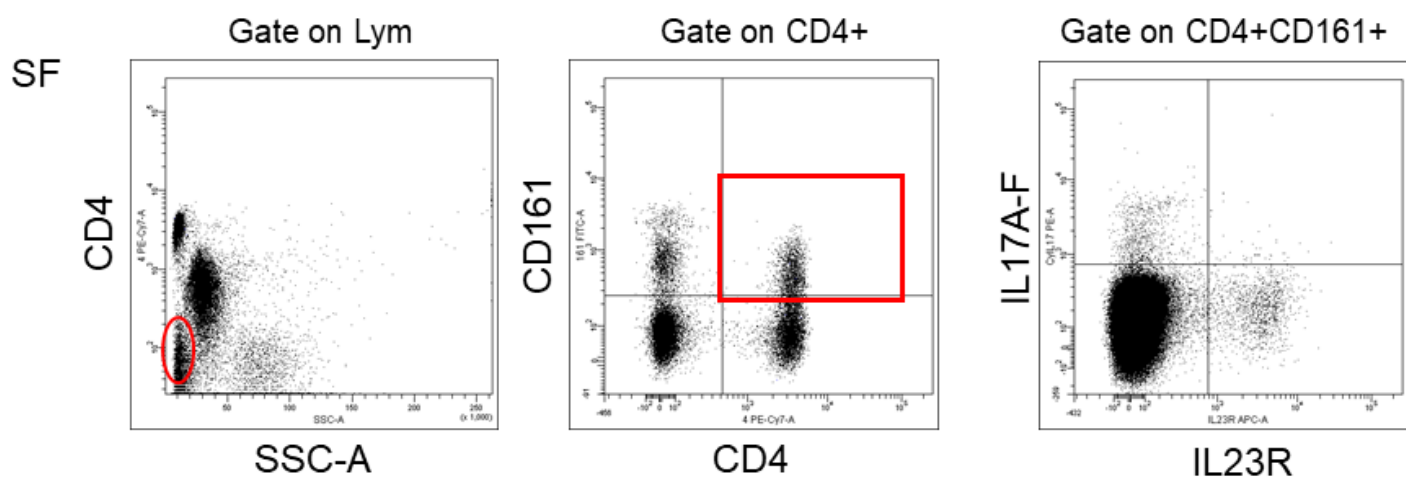

bottom

\begin{tabular}{lc}
\hline \multicolumn{1}{c}{ CD4+ T cells subtypes } & $\begin{array}{l}\text { Frequencies } \\
\text { (mean } \pm \mathrm{SD} \text { ) }\end{array}$ \\
\hline $\mathrm{CD}^{+}$ & \\
$\mathrm{CD} 4^{+} \mathrm{IL} 17 \mathrm{~A}-\mathrm{F}^{+}$ & $44.97 \pm 7.10$ \\
$\mathrm{CD} 4^{+} \mathrm{IL} 23 \mathrm{R}^{+}$ & $0.58 \pm 0.75$ \\
$\mathrm{CD} 4^{+} \mathrm{IL} 17 \mathrm{~A}-\mathrm{F}^{+} \mathrm{IL} 23 \mathrm{R}^{+}$ & $0.67 \pm 0.40$ \\
$\mathrm{CD}^{+} \mathrm{IL} 17 \mathrm{~A}-\mathrm{F}^{+} \mathrm{CD} 161^{+}$ & $0.07 \pm 0.91$ \\
$\mathrm{CD}^{+} \mathrm{IL} 17 \mathrm{~A}-\mathrm{F}^{+} \mathrm{CD} 161^{+} \mathrm{IL} 23 \mathrm{R}^{+}$ & $0.49 \pm 0.65$ \\
\hline
\end{tabular}


Fig. 2

Representative single compartment recirculation model (gamma variate with its integral) for representing CEUS kinetics (upper panel). The correspondent parameters are reported both on the curve and with the abbreviations and formulas (bottom panel).

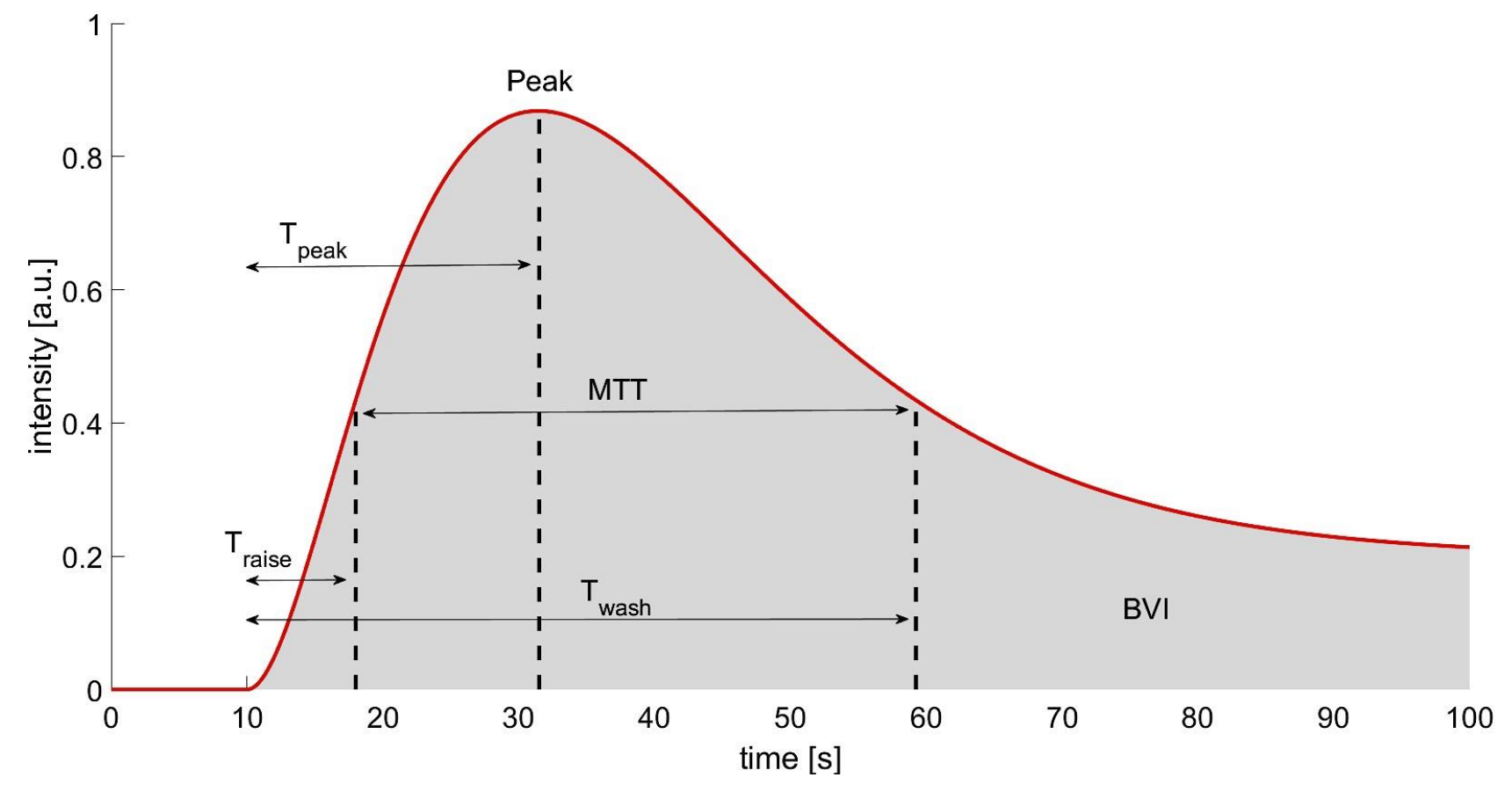

\begin{tabular}{|l|c|c|}
\hline \multicolumn{1}{|c|}{ Parameter } & Abbreviation & Formula \\
\hline $\begin{array}{l}\text { Time of the intensity curve to } \\
\text { reach half of its maximum value }\end{array}$ & T_raise & $\begin{array}{c}c_{S C R}\left(\boldsymbol{p}, T_{-} \text {raise }\right)=0.5 \cdot \text { Peak } \\
0<T_{-} \text {raise }<T_{-} \text {peak }\end{array}$ \\
\hline $\begin{array}{l}\text { Maximum value of the intensity } \\
\text { curve }\end{array}$ & Peak & $\max \left(c_{S C R}(\boldsymbol{p}, t)\right)$ \\
\hline $\begin{array}{l}\text { Time to reach the maximum } \\
\text { value of the curve }\end{array}$ & T_peak & $c_{S C R}\left(\boldsymbol{p}, T_{-} p e a k\right)=$ Peak \\
\hline $\begin{array}{l}\text { Time of the intensity curve to } \\
\text { reduce to half of its maximum } \\
\text { value }\end{array}$ & T_wash & $\begin{array}{c}c_{S C R}\left(\boldsymbol{p}, T_{-} w a s h\right)=0.5 \cdot P e a k \\
T_{-} p e a k<T_{-} w a s h<100\end{array}$ \\
\hline $\begin{array}{l}\text { Mean transit time } \\
\text { Blood volume index (area under } \\
\text { the curve) }\end{array}$ & MTT & MTT $=T_{-}$wash $-T_{-}$raise \\
\hline
\end{tabular}




\section{Fig. 3}

Representative false-color parametric map of blood volume index (BVI) superimposed on the correspondent B-mode ultrasound image of the synovium (left panel). The distribution of BVI values is represented (central panel) with its statistical descriptors. The descriptors allow the identification of regions of low and high BVI on the B-mode ultrasound image of the synovium (right panel).

Map of BVI values for each pixel within the synovia

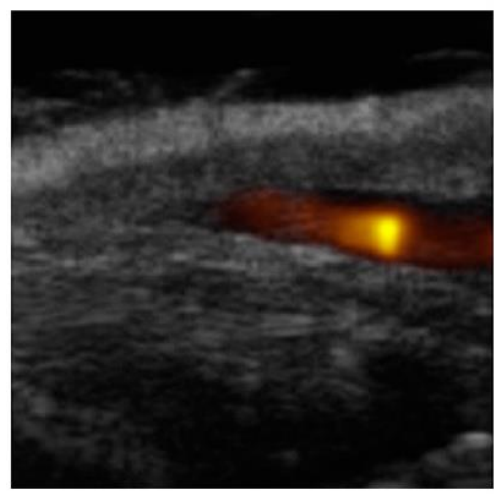

Distribution of BVI values and its statistcs

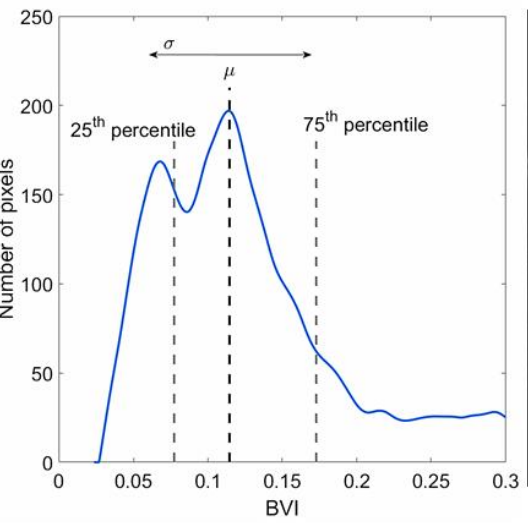

Representation of region of low-average-high BVI

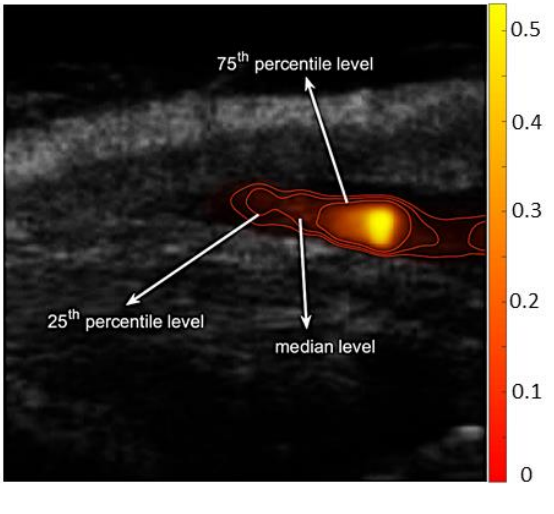

